\title{
Incidence and Risk Factors for Musculoskeletal Injuries among Indonesian Junior Badminton Athletes during a National Elite Championship
}

\author{
Finna A Suryanto, MD, ${ }^{1}$ Indah Suci Widyahening, MD, $\mathrm{PhD}^{2,3}$ and Ade Jeanne Tobing, $\mathrm{MD}^{2}$ \\ ${ }^{1}$ Sports Medicine Study Program, Department of Community Medicine, Faculty of Medicine, Universitas Indonesia, Jakarta, Indonesia \\ ${ }^{2}$ Department of Community Medicine, Faculty of Medicine, Universitas Indonesia, Jakarta, Indonesia \\ ${ }^{3}$ Southeast Asian Ministers of Education Organization - Regional Centre for Food and Nutrition (SEAMEO-RECFON) - \\ Pusat Kajian Gizi Regional (PKGR), Universitas Indonesia, Jakarta, Indonesia
}

\begin{abstract}
Objective. This study aimed to investigate the incidence and risk factors for musculoskeletal injuries among junior badminton athletes during a national championship.

Methods. A retrospective cohort study was conducted among 128 junior badminton athletes who were members of one Indonesian badminton club and participated in the National Premier Circuit held in June 2019 in West Java, Indonesia. Data on demographic characteristics, history of previous and current injuries, physical examination, diagnosis (type, anatomical structure involved, and location), and treatment of injuries were collected along with data on the format of the game (single, double, or combination), and the number of matches for each respective athlete. Measures of injury frequency used were the incidence proportion and clinical incidence. Determinant factors for incidence were investigated.
\end{abstract}

Results. Twenty-four injury events involving 23 athletes were recorded, with an incidence proportion of 23/128 athletes (18\%) and a clinical incidence of 24/128 athletes or 18.8 per 100 athletes. Acute injuries were more frequent $(13 / 24,54.2 \%)$ than chronic/overuse injuries. More than half $(14 / 24,58.3 \%)$ of the injuries occurred in the lower extremities. Factors that increased the risk of injury were age $\geq 15$ years (relative risk $[R R]=6.26,95 \%$ confidence interval $[\mathrm{Cl}] 1.96,20.04, \mathrm{p}<0.001)$, and the number of matches $\geq 3(\mathrm{RR}=3.79,95 \% \mathrm{Cl} 1.61,8.92, \mathrm{p}=0.001)$.

Conclusion. Musculoskeletal injuries occurred frequently among Indonesian junior badminton athletes during the national elite championship. An effective injury-prevention program specific to young athletes should be developed to maintain their future participation and performance in competition.

Key Words: badminton, injury, epidemiology, athlete, adolescent

\section{INTRODUCTION}

Badminton is a racket sport currently played by approximately 220 million people around the world and one of the most popular sports in most Asian countries. The sport is played by people of all ages and skill levels. In Asian countries, such as Indonesia, there are numerous badminton clubs spread throughout each country to facilitate community

Corresponding author: Indah Suci Widyahening, MD, PhD Department of Community Medicine

Faculty of Medicine

Universitas Indonesia

J. Pegangsaan Timur 16, Jakarta Pusat, Indonesia 10430

Email: indah_widyahening@ui.ac.id interest in this sport from an early age. Consequently, Indonesia has produced many world-class badminton athletes. ${ }^{1}$ Various badminton tournaments are also held to encourage the sport. The tournaments are divided into junior ( $<19$ years old) and adult ( $\geq 19$ years old) categories. 
Although badminton is classified as a non-contact sport with relatively lower injury rates than contact sports, the sport involves high-speed movement and various body postures that create high physical demands. A systematic review of badminton-related injuries among competitive badminton players showed that the injury incidence/prevalence was diverse among different populations. ${ }^{2}$ Further, the risk of injury was found to be higher or lower for juniors than for adults in different studies.

Understanding the epidemiology of injuries is vital to provide better planning and athlete health care and further the development of measures to prevent injuries and illness. Although many young people are interested in badminton globally, few studies have specifically addressed the epidemiology of injuries among junior badminton athletes. ${ }^{2,3}$ This study aimed to investigate the incidence and risk factors of musculoskeletal injuries in Indonesian junior badminton athletes during a national championship.

\section{METHODS}

\section{Study population and setting}

A retrospective cohort study was conducted that used the medical records and the register of 128 Indonesian junior badminton athletes who were members of one Indonesian badminton club and participated in the National Premier Circuit 2019 that was held in June 2019 in West Java for five consecutive days. All participating athletes were included as the study subjects from the beginning of the tournament until their last day of participation. Ethical clearance was obtained from the Research Ethics Committee of the Faculty of Medicine Universitas Indonesia - Cipto Mangunkusumo Hospital (FKUI-RSCM), with the number KET-948/UN2. F1/ETIK/PPM.00.02/2019.

The National Circuit (Sirnas) is a national-level championship that is used to foster Indonesian badminton athletes by using a point-collection system. Within 1 year, the Executive Board of the Indonesian Badminton Association (PB PBSI) held various National Circuit Championships (Sirnas Premier, A, and B). The National Circuits are held eight times a year, and four of them are part of the National Premier Circuit. ${ }^{4}$ The level of competition in the National Premier Circuit is different from the level of other National Circuits because the number of points and prizes obtained on the National Premier Circuit is similar to those on the international challenge. Athletes who have the highest point accumulations will be prioritized to become national training athletes. The badminton club that was taken as the study sample is the club that sent the second highest number of participants to this National Premier Circuit. The junior athletes were classified into five different categories on the basis of age groups: 1) <11 years old (Under-11/U-11), 2), $<13$ years old (Under-13/U-13), 3) $<15$ years old (Under15/U-15), 4), <17 years old (Under-17/U-17), and 5) $<19$ years old (Under-19/U-19). ${ }^{5}$

\section{Measurement of variables}

Data on the athlete's identity, demographic characteristics (age category and sex), history of a previous and current injury, physical examination, diagnosis of injury (type, anatomical structure involved, and location), and therapy were extracted from the medical records which were maintained by the club's physician for each of the participating athletes during the whole tournament. We also obtained data on the format of the game (single, double, or combination) and the number of matches for each respective athlete from the club register.

Musculoskeletal injuries were defined as any musculoskeletal symptoms that occurred during the tournament. Reports of pre-existing injuries or injuries not fully rehabilitated were excluded. Diagnosis of injury was made through history taking, physical examination, and if necessary, any imaging modalities, such as $\mathrm{x}$-ray, ultrasonography, and magnetic resonance imaging. The injuries were classified according to the type (acute or chronic/overuse), nature, or anatomical structure involved (strain, sprain, fracture, contusion, apophysitis, tendinopathy, or another injury), and the location (head and neck region, trunk, upper extremities, or lower extremities). The types, variety, and location of injuries were determined by the club's physician, a final-year sports medicine resident.

\section{Statistical analysis}

We used two different measures of injury in this study that was based on the description by Knowles et al. (2006): the incidence proportion, which is the number of injured athletes divided by the total number of athletes at risk, and the clinical incidence, calculated as the number of injuries per 100 athletes, which is also per the National Olympic Committee injury reporting system. ${ }^{6,7}$ The proportions of injury for each respective characteristic (type, nature, and location) were computed by dividing the number of corresponding events by the total injury events. Computation of relative risk with a $95 \%$ confidence interval (CI) was performed to analyze the relationship between the determinant factors (sex, age group, game format, and the number of matches) with the incidence proportion, as well as statistical testing using the chi-square test when appropriate. Multivariate analysis using Cox Regression was further conducted to calculate the adjusted relative risk and identify independent risk factors of the injury. Values of $p<0.05$ were considered to be statistically significant. Statistical analysis was performed by using the Statistical Package for Social Sciences version 20.0 (IBM SPSS Statistics for Windows, Armonk, NY). No missing data and lost to follow-up occurred in this study.

\section{RESULTS}

Slightly more male junior athletes (68/128, 53.1\%) participated in this study. The highest age group percentages were for the 13- to 14-year-old group (48/128, 37.5\%) and 
the 15 - to 16 -year-old group $(42 / 128,32.8 \%)$. More than half of the athletes $(84 / 128,65.6 \%)$ played the double-format game. The number of matches per athlete varied greatly (from 1-10 matches). There were 33 (25.8\%) athletes who only played one match in this tournament; on the other hand, there were also $26(20.3 \%)$ who played more than six matches. The characteristics of the athletes and the format of the badminton games are presented in Table 1.

Twenty-four events involving 23 athletes were recorded in this five-day tournament, and one athlete suffered two different injuries. Therefore, the incidence proportion was $23 / 128$ (18\%), whereas the clinical incidence was $24 / 128$ or 18.8 per 100 athletes. Table 2 presents the characteristics

Table 1. Characteristics of the junior athletes and format of the badminton game of one Indonesian badminton club that participated in the National Premier Circuit in June 2019

\begin{tabular}{lcc}
\multicolumn{1}{l}{$\mathbf{n}$ (athletes) $(\mathbf{n}=\mathbf{1 2 8})$} & $\%$ \\
Sex & 68 & 53.1 \\
$\quad$ Male & 60 & 46.9 \\
$\quad$ Female & & \\
\hline Age group (yrs.) & 14 & 10.9 \\
$11-12$ & 48 & 37.5 \\
$13-14$ & 42 & 32.8 \\
$15-16$ & 24 & 18.8 \\
$17-18$ & & \\
\hline Format of the game & 84 & 65.6 \\
Double & 33 & 25.8 \\
Single & 11 & 8.6 \\
Combination & & \\
\hline Number of matches & 70 & 54.7 \\
$\geq 3$ & 58 & 45.3 \\
\hline 3
\end{tabular}

of musculoskeletal injuries. Acute injuries were slightly more frequent $(13 / 24,54.2 \%)$ than chronic/overuse injuries. Based on its nature, tendinopathy was the most frequent $(7 / 24,29.2 \%)$ followed by strains $(5 / 24,20.8 \%)$ and other injuries $(4 / 24,16.7 \%)$. Other injuries reported in this tournament were cramps. Based on the injury location, more than half of the injuries were found to have occurred in the lower extremities (14/24, 58.3\%).

We found a significant relationship between the age group and the number of matches with the proportion of injured athletes (Table 3). The relationship was found to be consistent after controlling other co-factors using Cox regression analysis. Athletes aged $\geq 15$ years were more likely

Table 2. Characteristics of sports injuries among junior athletes who were members of one Indonesian Badminton Club that participated in the National Premier Circuit in June 2019 ( $n=24)$

\begin{tabular}{lcc} 
& $\mathrm{n}$ (events) & $\%$ \\
Type of injuries & & \\
$\quad$ Acute & 13 & 54.2 \\
$\quad$ Chronic & 11 & 45.8 \\
\hline Nature of injury & & \\
$\quad$ Sprain & 3 & 12.5 \\
Strain & 5 & 20.8 \\
Abrasion & 1 & 4.2 \\
Apophysitis & 2 & 8.3 \\
Tendinopathy & 7 & 29.2 \\
Blister & 2 & 8.3 \\
Others & 4 & 16.7 \\
\hline Location of injuries & & \\
Trunk & 3 & 12.5 \\
Upper extremities & 7 & 29.2 \\
Lower extremities & 14 & 58.3 \\
\hline
\end{tabular}

Table 3. Factors associated with sports injuries among the junior athletes who were members of one Indonesian Badminton Club that participated in the National Premier Circuit in June 2019

\begin{tabular}{|c|c|c|c|c|c|c|}
\hline & Injured n (\%) & Not injured n (\%) & Relative Risk (Cl 95\%) & p* & Relative Risk (Adj) (Cl 95\%) & $\mathbf{p}^{\dagger}$ \\
\hline \multicolumn{7}{|l|}{ Sex } \\
\hline Male & $13(19.1)$ & $55(80.9)$ & $1.15(0.54,2.42)$ & 0.720 & $1.63(0.69,3.85)$ & 0.26 \\
\hline Female & $10(16.7)$ & $50(83.3)$ & & & & \\
\hline \multicolumn{7}{|c|}{ Age group (yrs.) } \\
\hline$\geq 15$ & $20(30.3)$ & $46(69.7)$ & $6.26(1.96,20.04)$ & $<0.001$ & $4.19(1.20,14.71)$ & 0.03 \\
\hline$<15$ & $3(4.8)$ & $59(95.2)$ & & & & \\
\hline \multicolumn{7}{|c|}{ Format of the game } \\
\hline Single & $10(25.6)$ & $29(74.4)$ & $1.65(0.80,3.38)$ & 0.176 & $1.83(0.74,4.51)$ & 0.19 \\
\hline Double & $14(15.6)$ & $76(84.4)$ & & & & \\
\hline \multicolumn{7}{|c|}{ Number of matches } \\
\hline$\geq 3$ & $18(31.6)$ & $39(68.4)$ & $3.79(1.61,8.92)$ & 0.001 & $2.99(1.09,8.22)$ & 0.03 \\
\hline$<3$ & $6(8.3)$ & $66(91.7)$ & & & & \\
\hline
\end{tabular}

${ }^{*}$ Chi-squared test; ${ }^{\dagger}$ Cox regression 
to be injured (Adjusted relative risk $[$ Adj RR] $=4.19,95 \%$ Confidence Interval [CI] 1.20-14.71, $\mathrm{p}=0.025$ ). The number of matches $\geq 3$ was also one of the risk factors for injury to junior athletes (Adj RR = 2.99, 95\% CI 1.09-8.22, $\mathrm{p}=0.034$ ).

\section{DISCUSSION}

The incidence proportion of injury among the Indonesian junior badminton athletes was $18 \%$, whereas the clinical incidence was 18.8 per 100 athletes. Acute injuries were slightly more frequent than chronic/overuse injuries. According to the nature of the injuries, the three most frequent injuries were tendinopathy, strains, and cramps. More than half of the injuries were located in the lower extremities. Athletes aged $\geq 15$ years and those who participated in three or more matches were more likely to be injured.

The incidence proportion reported in this study is slightly higher than the rate of badminton injuries at the 2012 Summer Olympics in London (15.9\%), ${ }^{8}$ and a lower rate of badminton injuries (8.7\%) was also reported in the Rio de Janeiro 2016 Olympic Summer Games. However, the incidence proportion among youth competitive players (aged 13-16 years) in Malaysia was 57\%, whereas the clinical incidence was 109 per 100 athletes. $^{9}$ One study among Japanese junior national badminton players reported an injury incidence of 0.9 in male players and 1.3 in female players per 1000 hours, where 1 hour is equal to 1 hour of participation in a sport by one player. ${ }^{10}$ Our study focused on reporting injuries that occurred during one specific tournament, but both studies in Malaysia and Japan were 1-year longitudinal studies on the athletes in both practice and competitive environments.

More than $50 \%$ of the injuries in our study were acute injuries, including sprain, strain, abrasion, and cramps. The rates of acute and overuse injuries vary among young athletes in some reported studies. For example, the proportion of acute (strain/sprain/contusion) injuries in Malaysian junior badminton athletes was about three times higher than that of overuse injuries. ${ }^{9}$ However, opposite results were reported among Japanese young elite badminton players. ${ }^{10}$ The Malaysian study included young athletes age 13-16 years old which was more similar to our study while the Japan study included athletes up to the university level (age 13-21) which might explain the difference since older athletes might have an increased risk of injury which might persist during the study period.

The most common injury location in our study was the lower extremities, a finding that was also reported in a study among Malaysian junior badminton athletes as well as in a review by Senadheera. ${ }^{2,9}$ This injury location may be because of the rapid and repetitive lower extremity movements, such as lunges, running with high-speed changes of direction, or landing from jumps during the game, which places a heavy burden on the lower extremities. ${ }^{11}$ Tendinopathy, especially on the patellar, was the most frequently reported type of injury by the young athletes in our study. Knee problems were frequently observed among badminton athletes due to rapid eccentric concentric contraction of the quadriceps in the varying degrees of knee flexion and rotation that occurred repetitively and created high force loads on the patellar tendon. ${ }^{12}$ This type of injury could become recurrent and lead to chronification, which may affect the athlete's development and future career. ${ }^{13}$

The injury risk was six times higher for athletes aged $>15$ years than for younger ones. A study that investigated injuries among Japanese national-level badminton players in junior high school, high school, and university also concluded that the risk of injury increased with age and among Hong Kong elite badminton athletes. ${ }^{10,14}$ These findings can be explained by the fact that the mechanical load during matches increases with the level of competition, which usually also increases with age, and in turn increases the risk of injury. The increased mechanical loads also explained the increased risk of injury among athletes who compete in three or more matches, as observed in this study.

In our study, boys tended to have a higher frequency of injury than girls, although the difference was not statistically significant. Only a small number of studies have investigated the relationship between sex and injury risk among badminton players and the results were conflicting, as reported in the latest review about badminton-related injury among competitive players. ${ }^{2}$

An understanding of the most common types of injury and recognition of who is at risk are important steps toward the development of an effective injury prevention program. Such a program would be paramount in sustaining the performance of the young athletes as future professional athletes and a nation's assets.

Our study adds to the limited number of available studies on the epidemiology of injuries among badminton players, especially among young athletes. Although the tournament observed was only at the national level, it was the highest level of competition that resembled the physical demands of international competition. The use of the incidence proportion as a standardized measure of injuries makes the results translatable to the laypeople (coaches, players, media, parents) who need to understand the risk of injury among young badminton athletes. However, we only observed the incidence of injury during one competition, so it might not reflect the injury risk during practice or for recreational players.

\section{CONCLUSION}

Musculoskeletal injuries occurred frequently among Indonesian junior badminton athletes during a national elite championship. Athletes aged $\geq 15$ years and those who participated in three or more matches were more likely to be injured. Studying the epidemiology of injury among a specific population is important to describe the nature and 
extent of the injury problems to aid the development of an effective injury-prevention program specific to the target population.

\section{Ethics approval}

Ethical clearance was obtained from the Research Ethics Committee of the Faculty of Medicine Universitas Indonesia - Cipto Mangunkusumo Hospital (FKUI-RSCM), with the number KET-948/UN2.F1/ETIK/PPM.00.02/2019.

\section{Statement of Authorship}

All authors contributed in the conceptualization of work; acquisition and analysis of data; drafting and revising manuscript; and approved the final version submitted.

\section{Author Disclosure}

All authors declared no conflicts of interest.

\section{Funding Source}

This study was funded by the Universitas Indonesia Research Grant 2019, contract number NKB-0534/UN2. R3.1/HKP.05.00/2019.

\section{REFERENCES}

1. Badminton World Federation. BWF World Ranking. [Internet]. 2020 [cited 2020 Mar]. Available from: https://bwfbadminton. com/rankings/2/bwf-world-rankings/6/men-s-singles/2020/13/ ?rows=25\&page_no=1.

2. Senadheera VV. Epidemiological review of badminton-related injuries among competitive badminton players. J Phys Educ Sport. 2019; 4(3):41-4.
3. Steffen K, Engebretsen L. More data needed on injury risk among young elite athletes. Br J Sports Med. 2010; 44(7):485-9.

4. Indonesian Badminton Association. Badminton championship system. Jakarta: Indonesian Badminton Association; 2017. p. 65.

5. Badminton England. Badminton England age groups for juniors. [Internet]. 2019. [cited $2020 \mathrm{Mar}$. Available from: https://www. badmintonengland.co.uk/compete/badminton-england-age-groupsfor-juniors/.

6. Knowles SB, Marshall SW, Guskiewicz KM. Issues in estimating risks and rates in sports injury research. J Athl Train. 2006; 41(2): 207-15.

7. Soligard T, Steffen K, Palmer D, Alonso JM, Bahr R, Lopes AD, et al. Sports injury and illness incidence in the Rio de Janeiro 2016 Olympic Summer Games: a prospective study of 11274 athletes from 207 countries. Br J Sports Med. 2017; 51(17):1265-71.

8. Engebretsen L, Soligard T, Steffen K, Alonso JM, Aubry M, Budgett $\mathrm{R}$, et al. Sports injuries and illnesses during the London Summer Olympic Games 2012. Br J Sports Med. 2013; 47(7):407-14.

9. Goh SL, Mokhtar AH, Ali MRM. Badminton injuries in youth competitive players. J Sports Med Phys Fitness. 2013; 53(1):65-70.

10. Miyake E, Yatsunami M, Kurabayashi J, Teruya K, Sekine Y, Endo $\mathrm{T}$, et al. A prospective epidemiological study of injuries in japanese national tournament-level badminton players from junior high school to university. Asian J Sports Med. 2016; 7(1): e29637.

11. Reeves J, Hume PA, Gianotti S, Wilson B, Ikeda E. A retrospective review from 2006 to 2011 of lower extremity injuries in badminton in New Zealand. Sports. 2015; 3(2):77-86.

12. Peers KHE, Lysens RJJ. Patellar tendinopathy in athletes: current diagnostic and therapeutic recommendations. Sports Med. 2005; 35(1):71-87.

13. Bode G, Hammer T, Karvouniaris N, Feucht MJ, Konstantinidis L, Sudkamp NP, et al. Patellar tendinopathy in young elite soccer clinical and sonographical analysis of a German elite soccer academy. BMC Musculoskelet Disord. 2017; 18(1):344.

14. Yung PSH, Chan RHK, Wong FCY, Cheuk PWL, Fong DTP. Epidemiology of injuries in Hong Kong elite badminton athletes. Res Sports Med. 2007; 15(2):133-46. 